\title{
IDENTIFIKASI Trichophyton mentagrophytes PADA PEDAGANG IKAN PENDERITA TINEA PEDIS DI PASAR DAYA KOTA MAKASSAR
}

\author{
Dede Sulviana ${ }^{1)}$, Mujahidah Basarang ${ }^{2)}$, Andi Fatmawati ${ }^{2)}$ \\ 1) Klinik Tirta Medical Centre \\ 2) Program Studi DIII Teknologi Laboratorium Medis Politeknik Kesehatan Muhammadiyah Makassar \\ Alamat Korespondensi: dedesulviana@gmail.com
}

\begin{abstract}
Abstrak
Tinea pedis adalah penyakit infeksi jamur dermatofita tersering yang ditemukan di daerah kulit telapak kaki dan sela jari kaki. Beberapa faktor risiko Tinea pedis adalah penggunaan sepatu tertutup yang lama setiap hari, pemakaian kaus kaki ketika bekerja, dan paparan jamur. Penelitian ini dilakukan pada pedagang ikan yang sehari-harinya bekerja di tempat yang lembab karena berhubungan langsung dengan air dan memakai sepatu tertutup dala m jangka waktu yang lama yang dilakukan di Pasar Daya kota Makassar. Tujuan dari penelitian ini adalah untuk mengetahui ada tidaknya jamur Trichophyton mentagrophytes pada pedagang ikan penyebab Tinea pedis di pasar Daya Kota Makassar. Sampel yang diteliti adalah 10 sampel kerukan kulit kaki pedagang ikan yang diteliti melalui teknik kultur pada media SDA kemudian diuji konfirmasi melalui teknik mikroskopis. Hasil penelitian sebanyak 10 sampel kerokan kulit telapak kaki dan sela jari kaki pada pedagang ikan di pasar Daya Kota Makassar terdapat 1 orang yang terinfeksi jamur Trichophyton mentagrophytes.
\end{abstract}

Kata Kunci: Trichophyton mentagrophytes, tinea pedis, pedagang ikan

\section{PENDAHULUAN}

Dermatofitosis merupakan penyakit yang disebabakan oleh jamur dermatofita dimana kelompok jamur ini yang memiliki kemampuan untuk melekat pada keratin dan menggunakannya sebagai sumber nutrisi yang memungkinkan jamur tersebut untuk berkoloni pada jaringan yang mengandung keratin, sepertiepidermis (kornea kulit), rambut dan kuku. Penyakit ini dapat menyerang semua umur(Nuryanti,2016). Penularan dermatofitosis dapat terjadi melalui kontak langsung dengan hewan yang terinfeksi dan manusia atau dengan kontak tidak langsung dengan fomit yang terkontaminasi (Siregar,2008). Penyakit yang tergolong dermatofitosis adalah tinea pedis, tinea kapitis, tinea korporis, tinea kruris, tinea ungium, tinea barbae,dan tinea imbrikata (Sondakh, 2016).
Salah satu dermatofitosis yang sering terjadi adalah tinea pedis, athlete's foot atau ringworm of the footyang menginfeksi sekitar $10 \%$ populasi dunia pada daerah tumit, sela-sela jari, telapak kaki dan bagian lateral kaki (Napitupulu, 2016). Salah satu penyebab penyakit ini adalah Trichophyton mentagrophytes (Rihatmadja,2008).

Trichophyton mentagrophytes merupakan jamur zoofilik yang menyerang kulit yang menggunakan keratin sebagai nutrisinya. Keratin adalah protein utama dalam kulit, rambut dan kuku (Faradilla, 2009). Dimana memiliki granuler sampai berbentuk seperti serbuk dan biasanya menunjukkan bentuk seperti tangkai buah anggur terdapat banyak tangkai-tangkainya (Djide, 2007). Memiliki bentuk makrokopis seperti tenunan lilin, berwama putih sampai putih kekuningan yang agak terang atau berwama violet merah, bahkan berwarna 
pucat kekuningan dan coklat (Faradilla,2009).

Berdasarkan penelitian yang dilakukan oleh Lee (2014) Trichophyton mentagrophytes adalah dermatofita umum kedua di Korea. selama 21-tahun-periode 1992-2012, 6.250 pasien dengan Trichophyton mentagrophytes disurvei untuk menentukan kejadian tahunan dan distribusi subyek berdasarkan usia, jenis kelamin, musim, situs yang terlibat, dan topografi.Analisis epidemiologis menunjukkan bahwa kejadian tahunan mencapai puncaknya pada tahun 2005, dan kemudian secara bertahap menurun. Infeksi Trichophyton mentagrophytes paling umum pada bulan Juli dimana pada bulan ini masa peralihan dari musim panas ke musim dingin. Ditemukan terutama pada orang dewasa setengah baya, terutama pada mereka yang berusia empat puluhan terinfeksi Trichophyton mentagrophytes.

Faktor pertumbuhan Trichophyton mentagrophytes dipengaruhi keadaan seperti iklim tropis, bertambahnya kelembaban karena keringat, pecahnya kulit karena mekanis, tingkat kebersihan perorangan, dan paparan terhadap jamur (Kurniawati,2006). Selain daripada itu perkembangbiakan Trichophyton mentagrophytes terdapat Infeksi tinea pedis yang dapat menyerang berbagai tingkat pekerjaan juga, khususnya pekerjaan yang menuntut pemakaian sepatu yang ketat dan tertutup, lingkungan yang hangat dan lembab yang akan mempengaruhi pertumbuhan jamur dan penyebarannya (Kumar et al.2011). Pekerja pengguna sepatu tertutup memiliki proporsi 2 kali lebih besar untuk mengalami Tinea pedis bila dibandingkan dengan pengguna sepatu berongga (Lestari,2015).

Profesi yang sering menggunakan sepatu tertutup adalah pedagang ikan yang sehari harinya bekerja di pasar. Lingkungan tempat aktivitasnya seperti pasar memiliki keadaan yang lembab dan berhubungan langsung dengan air, disertai berada di daerah tropis dapat mengakibatkan pertumbuhan jamur makin subur (Amiruddin,2003).

Pekerjaan yang memakai sepatu tertutup (bot) selain pedagang ikan ialah polisi lalu lintas, pemulung sampah, dan lain-lain. Menurut Napitupulu (2016), dari 41 sampel ditemukan 41,5\% angka kejadian penderita tinea pedis pada polisi lalu lintas. Dimana lama pemakaian sepatu yang lebih dari 8 jam berjumlah 35 orang, rentan terkena tinea pedis $92,7 \%$ dan pemakaian kurang dari 8 jam berjumlah 3 orang terkena tinea pedis $7,3 \%$. Pemakaian sepatu tertutup (bot) menjadi faktor yang menguntungkan bagi jamur untuk berkembang biak (Kumar et al. 2011). Berdasarkan survey yang dilakukan oleh peneliti di pasar daya terlihat bahwa ratarata pedagang ikan di pasar tersebut mengunakan sepatu tertutup dan terjangkit penyakit tinea pedis. Berdasarkan uraian di atas peneliti tertarik untuk mengidentifikasi Trichophyton mentagrophytes pada pedagang ikan penderita tinea pedis.

\section{METODE PENELITIAN}

\section{Alat dan Bahan}

Alat yang di gunakan adalah autoklaf, hot plate, gelas kimia, pipet tetes , cawan petri, batang pengaduk, neraca analitik, deck glass, objek glass, erlenmeyer, lampu spirtus, mikroskop, dan nall/ose.

Bahan-bahan yang digunakan dalam penelitian ini adalah kerokan kaki, media SDA (Sabouraud Dextrose Agar), alkohol, Teamphenicol dan $\mathrm{KOH} 10 \%$.

\section{Prosedur Kerja}

Persiapan Sampel

Disiapkan alat dan bahan yang akan di gunakan. Didisinfeksi sela-sela jari kaki yang akan di kerok dengan menggunakan kapas alkohol. Lalu sela-sela jari kaki dikerok dengan menggunakan scalpel dan 
di kumpulkan elemen sela-sela jari yang telah di kerok dan di letakkan dalam wadah sampel yang steril seperti amplop/petri disk.

Sterilisasi Alat

Sebelum memulai pembuatan media, terlebih dahulu disterilkan alat-alat yang akan digunakan seperti, erlenmeyer, gelas ukur, batang pengaduk, sendok tanduk dan cawan petri dengan menggunakan autoklaf pada suhu $121^{\circ} \mathrm{C}$ selama 15 . menit.

Pembuatan Media SDA

Ditimbang media SDA sebanyak 14,3 gr yang di peroleh dari Dipindahkan serbuk media SDA kedalam gelas beker, lalu ditambahkan aquadest sebanyak $220 \mathrm{~mL}$, dipindahkan ke dalam erlenmeyer, larutan dihomogenkan dengan bantuan pemanasan dan pengadukan, pelarutan tidak boleh sampai mendidih pelarutan harus sempurna sehingga tidak ada kristal yang tersisa), dan mulut erlenmeyer ditutup dengan kapas, disterilisasi di dalam autoklaf selama 15 menit, pada suhu $121^{\circ} \mathrm{C}$, dengan tekanan 1-2 atm kemudian tambahkan Teamphenicol dan homogenkan. Setelah proses sterilisasi selesai, dikeluarkan media dari autoklaf dan dibiarkan larutan hingga suhu $\pm 50^{\circ} \mathrm{C}$ lalu kemudian dihomogenkan. Disiapkan petridish diatas meja yang datar, bersih, dan kering, lalu media dalam Erlenmeyer tadi dituangkan kira-kira 15-20 mL kedalam petridish.

Pemeriksaan Langsung

Disiapkan alat dan bahan yang akan digunakan seperti sampel, mikroskop, bunsen, objek glass, cover glass, ose . Dibersihkan objek glass dengan alkohol agar bebas lemak kemudian sampel diletakkan di atas objek gelas, beri 1 tetes larutan $\mathrm{KOH} 10 \%$ sampai merata dan tutup dengan cover glass. Lalu difiksasi dengan api bunsen agar jamur tersebut melekat pada cover glass. Diperiksa dibawah mikroskop dengan pembesaran 10x untuk mencari lapangan pandang kemudian ke pembesaran $40 \mathrm{x}$,lalu amati. Positif jika ditemukanmikrokonidia banyak, menggerombol seperti buah anggur atau tunggal seperti tetes air mata Makrokonidia berbentuk seperti rokok atau pensil, multiseluler (3-4 sel) (Ariyana, 2016).

Kultur sampel

Sebagaian spesimen tersebut dibiakkan pada Sabouraud Dextrose Agar dan biakan suhu $\operatorname{kamar}\left(25-30^{\circ} \mathrm{C}\right)$ Isolasi awal yakni skuama digores pada medium sabouraud dekstrosa agar pada cawan petri dan diinkubasi pada suhu $32-34^{\circ} \mathrm{C}$. Dilakukan pengamatan pertumbuhan koloni jamur setiap hari sampai hari ke-5/ke-7. Hasil positif jika terbentuk koloni berwarna Kuning kecoklatan sampai coklat kemerahan dengan teksur halus seperti kapas (Amiruddin,2003).

\section{HASIL DAN PEMBAHASAN}

Berdasarkan penelitian pada 10 sampel kerukan kulit kaki pedagang ikan di pasar Daya kota Makassar yang dilaksanakan di laboratorium Mikrobiologi Analis kesehatan Muhammadiyah Makassar diperoleh hasil sebagai berikut:

Tabel1. Hasil pemeriksaan Trichophyton mentagrophytes pada Penderita Tinea Pedis pada Pedagang Ikan di Pasar Daya Kota Makassar.

\begin{tabular}{|c|c|}
\hline Sampel & Jenis Jamur \\
\hline PI 1 & Aspergillus fumigatus \\
\hline PI 2 & $\begin{array}{l}\text { Aspergilus fumigatus } \\
\text { Trichosporon } s p\end{array}$ \\
\hline PI 3 & $\begin{array}{l}\text { Aspergillus fumigatus } \\
\text { Tricophyton mentagrophytes }\end{array}$ \\
\hline PI 4 & Aspergillus fumigatus \\
\hline PI 5 & $\begin{array}{l}\text { Aspergillus fumigatus } \\
\text { Malassezia furfur } \\
\text { Rhhodotorula sp }\end{array}$ \\
\hline PI 6 & Malassezia furfur \\
\hline PI 7 & Alternaria sp \\
\hline
\end{tabular}




\begin{tabular}{|c|c|}
\hline PI 8 & Aspergillus fumigatus \\
\hline PI 9 & $\begin{array}{l}\text { Aspergilus fumigatus } \\
\text { Malassezia furfur }\end{array}$ \\
\hline
\end{tabular}

PI 10 Aspergillus flavus

Dari data hasil penelitian tabel 1 di atas, dapat dikatakan bahwa salah satu kaki pedagang ikan di Pasar Daya kota Makassar terinfeksi oleh Trichophyton mentagrophtes dengan pertumbuhan koloni pada media SDA kulturnya rata, koloni halus dan lembut seperti kapas, datar dan seperti tenunan lilin, berwama putih pucat kekuningan. Adapun pemeriksaan mikroskopik yang di dapatkan yaitu hifa seperti spiral, mikrokonidia berbentuk kelompok padat seperti buah anggur dan makrokonidia berbentuk seperti puntung rokok.

Penelitian ini bersifat observasi laboratorik yang bertujuan untuk mengidentifikasi keberadaan Trichophyton mentagrophtes penderita tinea pedis pada pedagang ikan di pasar daya kota Makassar. Proses identifikasi terhadap sampel penelitian diawali dengan mengumpulkan 10 orang penderita Tinea pedis di pasar Daya yang kesehariannya menggunakan sepatu bot. Pengambilan sampel dilakukan secara purposive sampling dengan menggunakan scalpel dengan mengkeruk kulit bagian kaki yang terinfeksi Tinea pedis kemudian sampel dikultur pada media Sabaraud Dextrose Agar (SDA).

Pemeriksaan 10 sampel ini dimulai dengan penanaman pada media Sabaroud Dextrose Agar (SDA), dilakukan inokulasi sampel pada media SDA kemudian diinkubasi dengan suhu kamar selama seminggu. Hasil yang diperoleh setelah masa inkubasi menunjukkan adanya pertumbuhan pada semua sampel yang akan diperiksa. Setelah dilakukan pemeriksaan, baik itu secara makroskopik maupun mikroskopik terdapat sampel yang menunjukkan hasil positif terinfeksiTrichophyton mentagrophtes.

Hasil penelitian yang diperoleh menunjukkan bahwa positif ditumbuhi Trichohyton mentagrophtes yaitu pada sampel 3 dengan ciri-ciri koloni berwarna putih sampai krem dengan permukaan koloni halus, lembut seperti kapas dan datarseperti tenunan lilin, berwama putih pucat kekuningan.Ciri- ciri untuk pemeriksaan mikroskopikadalah hifa seperti spiral, mikrokonidia berbentuk kelompok padat seperti buah anggur dan makrokonidia berbentuk seperti puntung rokok.

Trichophyton mentagrophytes merupakan jamur zoofilik yang termasuk dalam genus dermatofita yang dapat menyerang jaringan kulit pada jari-jari kaki, telapak kaki, dan bagian lateral kaki dan menyebabkan infeksi kulit yaitu tinea pedis.Kondisi lingkungan di Indonesia yang beriklim tropis mempunyai daya dukung yang sangat baik untuk pertumbuhan dan perkembangan mikroorganisme, baik yang menguntungkan dan merugikan. Salah satu mikroorganisme yang merugikan adalah Trichohyton mentagrophtes yang tumbuh dengan baik pada keadaan lembab. Jamur ini akan tumbuh dibagian bagian tubuh tertentu pada manusia dan akan menimbulkan penyakit, Kelainan mengenai kulit sering terjadi pada bagian jari-jari kaki, terutama antara jari ketiga dengan keempat dan keempat dengan kelima, telapak kaki dan bagian lateral kaki yang disebut tinea pedis. Faktor tumbuhnya jamur Trichohyton mentagrophytes dapat muncul karena penggunaan sepatu tertutup dan memakai kaos kaki dengan waktu yang lama sehingga mendukung tumbuhnya jamur dengan keadaan yang lembab. Selain karena pemakaian sepatu tertutup untuk waktu yang lama, Individunya kurang memperhatikan kebersihan pribadinya terutama pada sela-sela jari kaki yang selalu 
basah oleh keringat merupakan suatu keadaan yang sangat mudah untuk pertumbuhan jamur dan ditambah lagi keadaan kulit dari individu tersebut yang cocok dengan Trichohyton mentagrophytes.

Hasil penelitian untuk sampel yang lainnya ditemukan jenis jamur lain, ini dikarenakan kaki pedagang ikan lainnya yang telah terkontaminasi oleh jamur lain pada saat pengambilan sampel atau dari sampel itu sendiri. Sampelyang terinfeksi oleh jamurlain adalah sampel 1, 3, 4, 8 dan 9 didapatkan koloni berwarna birudengan permukaan seperti beludru yang terdiri dari konidia yang padat. Setelah diamati secara makroskopik dan mikroskopik diidentifikasi sebagai Aspergillus fumigatus. Pada sampel 2 didapatkan koloni berwarna putih dan diidentifikasi trichosporon sp. Pada sampel ke 5 ditemukan Koloni berbentuk bulat atau oval berwarna merah seperti salmon atau sedikit orange, halus hingga keriput, sangat mengkilap dan koloni yang keras dan seperti ragi. Setelah diamati secara makroskopik dan mikroskopik diidentifikasi Rhodotorula sp. Pada sampel ke 6, 8, dan 9 ditemukan koloni berbentuk oval dan bulat atau seperti botol bergerombol dan berwarna putih. Setelah diamati secara makroskopik dan mikroskopik diidentifikasi Malassezia furfur. Pada sampel 7 ditemukan koloni berbentuk lensa dan berwarna berwarna putih sampai kecokelatan hingga kehitaman. Setelah diamati secara makroskopik dan mikroskopik diidentifikasi Alternaria $s p$. Untuk sempel ke 10 ditemukan koloni berwarna hijau berkabut dengan tekstur seperti beludru. Setelah diamati secara makroskopik dan mikroskopik diidentifikasi Aspergillus flavus.

\section{KESIMPULAN}

Berdasarkan hasil pemeriksaan yang dilakukan terhadap 10 spesimen kerukan kulit kaki pada pedagang ikan pada media
SDA diientifikasi bahwa hanya 1 sampel yang ditemukan pertumbuhan Trichophyton mentagrophtes.

\section{DAFTAR PUSTAKA}

Amiruddin, M.D. 2003.Penyakit Kulit.

Bagian Ilmu Penyakit Kulit dan

Kelamin FK UNHAS. Makassar.

Ariyana,D. 2016. Identifikasi Spesies Jamur

Pada Rumah Makan Di Kawasan

Stasiun Gubeng Surabaya. Back issue vol 3. No. 2 ISSN 2597-3681

Djide,N.M.2007.Mikrobiologi III(Mikologi Dan Virologi) Teknologi Laboratorium Kesehatan.Makassar.

Faradilla, N., Nababan, M., dan Mardhiya, W.R. 2009. Kerion Celsi. FK UNRI. Pekanbaru.

Kumar,V.,Tilak,R.,Prakash,P.,Nigam.C.,Gu pta,R.2011.Asian Journal Of Medical Sciences 2(2011) 134-138 Tinea Pedis.

Kurniawati. 2006.Faktor - faktor yang berhubungan dengan kejadian tinea pedis pada pemulung di TPA Jatibarang Semarang. Ilmu Kesehatan Lingkungan Universitas Diponegoro : Semarang.

Lee,W.J.I., Park,H.K., Kim,S.M., Lee,J.S., Kim,W.D., Bang,J.B., Jun, B, J.,2014.Decreasing Incidence of Trichophyton mentagrophytes in Korea: Analysis of 6,250 Cases during the Last 21-Year-Period (1992-2012).journal of korean medical science.

Lestari, I. D. 2015. Efek Penggunaan Pelindung Kaki Yang Tertutup Dibandingkan Dengan Berongga Terhadap Tinea Pedis Pada Operator Cucian Mobil Di Perusahaan Waralaba Pencucian Mobil. Program Studi Megister Kedokteran Kerja : Jakarta.

Napitupulu, A.N. 2016. Prevalensi Dan Faktor Terjadinya Tinea Pedis Pada 
Polisi Lalu Lintas Kota Semarang, Tembalang-Semarang. Jurnal Kedokteran Diponegoro Vol 05, No 04.

Nuryanti,S. 2016.Aktivitas Antifungi Temu Putih (Curcuma Zedoaria) Terhadap Trichophyton Mentagrophytes.As-Syifaa Vol 08 (02) : Hal. 50-57, Desember 2016 ISSN : 2085-4714 .

Rihatmadja, R. 2008. Anatomi Dan Faal Kulit. FKUI: Jakarta.

Siregar, 2008. Penyakit Jamur Kulit. EGC Lia Astika Sari : Jakarta.

Sondakh, C., E., E., J., Pandaleke, A., T., Mawu, O., F.2016. Profil dermatofitosis di Poliklinik Kulit dan Kelamin RSUP Prof. Dr. R. D. Kandou Manado periode Januari Desember 2013.Jurnal e-Clinic (eCl) Vol 4, No. 1. 